Psychological Medicine, 1999, 29, 1-8. Printed in the United Kingdom

(C) 1999 Cambridge University Press

EDITORIAL

\title{
Will the novel antipsychotics significantly ameliorate neuropsychological deficits and improve adaptive functioning in schizophrenia ${ }^{1}$
}

The recent and pending introduction of new antipsychotic medications carries the hope of a significant advance in the treatment of schizophrenia. Although the propensity of these agents to cause fewer motor side-effects than conventional neuroleptics may lead to improved compliance and clinical effectiveness, the promise of a significant impact upon the lives of patients may primarily reside in the evidence that the atypicals alleviate negative features such as emotional flattening, social withdrawal and impoverished speech. Auditory hallucinations and delusional thinking are the more dramatic expressions of illness, but these negative symptoms, along with neuropsychological deficits, are arguably more responsible for the persisting debilitation exhibited by schizophrenics (McKay, 1980; Pogue-Geile \& Harrow, 1985; Breier et al. 1991; Crow, 1991; Mukherjee et al. 1991; Kane \& Freeman, 1994; Perlick et al. 1992; Green, 1996; Green et al. 1997). Negative symptoms and neuropsychological deficits are minimally responsive to conventional neuroleptics (Goldberg et al. 1991; Meltzer, 1992; Lee et al. 1994; Meltzer et al. 1994), leaving schizophrenics ill-equipped to deal with the demands of normal living.

The claim is often made that clozapine alleviates both negative symptoms and neurocognitive deficits (e.g. Meltzer, 1995a). Although there is hope that the newer antipsychotics will do likewise, the evidence for neurocognitive gains in particular is, so far, limited. Only a few studies of the effects of novel antipsychotics (such as risperidone, olanzapine, sertindole and related in-trial agents) on neuropsychological functioning have been undertaken. When effects have been demonstrated, their significance has remained unclear.

This state of affairs is unsatisfactory, as a positive impact upon neuropsychological functioning would be of interest for more than just clinical reasons. An amelioration of cognitive deficiencies would suggest that these features are not inexorably tied to an irreversible pathology, such as gross neurodevelopmental aberrations or loss of neural tissue. Rather, such gains would suggest a treatable underlying pathophysiology, lending hope to other treatments, including cognitive rehabilitation. Since these deficits are increasingly viewed as fundamental to our conceptions of severe psychiatric illness (Goldberg et al. 1991; Green, 1996; Nuechterlein \& Subotnik, 1996), neurocognitive changes might reciprocally shed light on these medications and schizophrenia. Finally, differential effects on cognition across medications should be factored into cost-benefit analyses, particularly when these effects are accompanied by broader adaptive functioning gains.

Is there any reason to believe that the novel antipsychotics will significantly improve the functional capacities of schizophrenics? Several considerations are relevant, including purported action mechanisms, animal behaviour findings, neurological effects, negative symptoms effects and existing cognitive outcome data.

\section{ANTIPSYCHOTIC MECHANISMS AND THEIR IMPLICATIONS FOR COGNITION}

If the mechanisms of action of novel antipsychotics differ from those of conventional neuroleptics, different behavioural systems may be impacted. The novel drugs are commonly labelled 'serotonin-dopamine antagonists' because their primary action is commonly presumed to be a

1 Address for correspondence: Dr Keith Hawkins, Department of Psychiatry, Yale University School of Medicine, 34 Park Street, New Haven, CT 06519, USA. 
serotonin 5- $\mathrm{HT}_{2}$ receptor blockade combined with $\mathrm{D}_{2}$ receptor blockade (Megens et al. 1994; Huttunen, 1995).

Whether the mechanisms are quite that simple is unclear. Clozapine has arguably been more extensively studied than the newer agents, yet uncertainties persist regarding its modes of action. There may be a targeting of specific anatomical systems (e.g. the mesolimbic and mesocortical dopamine agonist (DA) neuronal systems), with minimal adverse impact on other DA systems (nigrostriatal elements of basal ganglia and pituitary tuberoinfundibular system), resulting in less of the extrapyramidal symptoms (EPS) or oligomenorrhoea associated with the much broader DA effects of neuroleptics. Alternatively, DA and serotinin systems effects may be combined with numerous others (e.g. upon norepinehrine, acetylcholine, glutamate, specific neuropeptides systems), or there may be a selective affinity for the DA receptor subtypes $\mathrm{D}_{1}$ and $\mathrm{D}_{4}$, along with $\mathrm{D}_{2}$ (Leiberman, 1996).

Among these complexities, it is certain that any receptor mechanisms that relate to cognitive effects will vary across the atypical and novel antipsychotics. Clozapine and olanzapine have high $\mathrm{M}_{1}$ affinities similar to the neuroleptic thioridazine, whereas risperidone and quetiapine (Richelson, 1996), along with sertindole (Jibson \& Tandon, 1996), show low $M_{1}$ muscarinic affinity, similar to haloperidol. A relative absence of muscarinic $M_{1}$ receptor activity should result in fewer anticholinergic side effects (Jibson \& Tandon, 1996), including memory impairment; on the other hand, clozapine and other intrinsically anticholinergic medications might be expected to diminish memory functioning. The need for adjunctive anticholinergic medications varies across agents, further complicating cognitive outcome.

\section{NEUROLOGICAL RISKS}

The impact of neuroleptics upon motor systems might be expected negatively to impact broader aspects of functioning, as the basal ganglia have also been implicated in sensory, attention, memory and cognitive processes (Lidsky et al. 1981). Conversely, a lesser impact of a novel agent upon these systems should leave the individual more intact.

The novel antipsychotics do cause fewer extrapyramidal side-effects (Kane \& Freeman, 1994; Meltzer et al. 1994; Borison, 1995), a clinical reflection of laboratory findings. In rats, risperidone is 4-10 times less potent than haloperidol as a central $D_{2}$ antagonist, and may be as much as 33 times less potent for complete blockade of motor activity than haloperidol (Megens et al. 1994). Relatively higher doses are required to induce catalepsy relative to haloperidol (Megens et al. 1994). Olanzapine antagonizes 5-HT induced head twitches in mice at much lower doses than those required to block apomorphine-induced climbing behaviour, suggesting that it is a more potent 5$\mathrm{HT}_{2}$ than dopamine antagonist (Moore et al. 1992). These lesser DA effects suggest that the risk for tardive dyskinesia (TD) may be lower (Meltzer et al. 1994; Jibson \& Tandon, 1996), and there have been reports that at least one novel agent, risperidone, actually has a beneficial effect on TD (Chouinard et al. 1993).

Unfortunately, the neuropsychological implications of this more benign effect upon motor systems remain uncertain for several reasons. First, the impact of neuroleptics upon neuropsychological functioning appears not to be pronounced. Fine motor coordination or speed deficits may occur, along with an anticholinergic impact upon memory (both directly and from adjunctives such as benzotropine). Overall, however, neuroleptics appear to exert a rather subtle influence, which includes beneficial as well as detrimental effects (Spohn \& Strauss, 1989; Goldberg et al. 1991). Deficits are evident pre-medication exposure (Andreasen et al. 1992; Goldman, 1998), and little evidence tying chronic use to neuropsychological deficiency has emerged (Goldman, 1998). Any deficits that can be laid at the door of neuroleptics are likely to pale in comparison with the persisting deficiencies intrinsic to the illness (Goldberg et al. 1991; Saykin et al. 1994; Goldman, 1998).

Secondly, the relationships between neuroleptic treatment, TD, and neuropsychological deficiency remain in dispute. The argument that $T D$ is simply the result of $\mathrm{D}_{2}$ receptor 
supersensitivity due to prolonged post-synaptic blockade in the caudate and putamen (Cohen \& Cohen, 1993), and the belief that TD-correlated neuropsychological deficits are thereby also caused by chronic neuroleptic use, has frequently been questioned. Neuropsychological deficits precede and appear to be risk factors for TD (Struve \& Willner, 1983; Goldman, 1998), suggesting that TD may emerge in neurobiologically vulnerable individuals (Goldman, 1998). Although neuroleptic exposure may, therefore, be an insufficient cause of TD, it may often be a necessary one, wherein neuroleptics interact with the vulnerability to produce the syndrome (Struve \& Willner, 1983). If so, some degree of neuropsychological deficiency may be attributable to its emergence. Nevertheless, on balance, the neurocognitive advantages over neuroleptics accruable to a lesser negative neurological impact of the novel agents seem likely to prove to be relatively minor.

\section{NOVEL ANTIPSYCHOTICS AND NEGATIVE SYMPTOMS}

Since neuropsychological deficiencies tend to correlate with negative rather than positive symptoms (Breier et al. 1991; Goldberg et al. 1991; Perlick, et al. 1992, Hawkins et al. 1997; Goldman 1998), a reduction in negative symptoms would hold forth hope for an accompanying improvement in neuropsychological functioning.

The novel antipsychotics do reduce negative symptoms (Gelders, 1989; Meco et al. 1989; Chouinard et al. 1993; Kane \& Freeman, 1994; Marder \& Meibach, 1994; Schooler, 1994; Borison, 1995; Huttunen, 1995), but whether these improvements reflect an ameliorated pathophysiology primary to negative symptoms remains hotly debated. Much of the evidence stems from comparisons of an atypical with a placebo or haloperidol. Reductions in negative symptoms relative to the placebo condition may be secondary to reduction in psychosis in the treatment group (e.g. reduced paranoia results in improved sociality), rather than reflecting an improvement in a core deficit. In comparisons with haloperidol, the advantage of the atypical may additionally reflect reductions in EPS (psychomotor slowing, facial inexpressiveness, etc.), resulting in an apparent improvement in negative features. Careful distinctions between primary negative symptoms (reflecting pathophysiological processes independent of those responsible for positive symptoms) and negative features secondary to positive symptoms become critical to the resolution of this issue.

Although a consensus across approaches to this problem may be emerging (e.g. Carpenter et al. 1991; Crow, 1991; Mukherjee et al. 1991), with features such as poverty of speech and affective nonresponsivity being viewed as primary (deficit state) negative features, the issue of disentangling primary from secondary features remains a difficult one. Kane (1996), for example, argues that primary features and those due to drug-induced parkinsonism are 'truly confounded', noting that the detection of extrapyramidal symptoms in neuroleptic-naive patients indicates that primarysecondary dichotomies are likely to be misleading. Carpenter and colleagues argue the need for a longitudinal approach to the assessment of negative symptoms, as core deficit features endure over time (Carpenter et al. 1988; Kirkpatrick et al. 1989).

Is there evidence that atypical or novel antipsychotics directly address primary deficit-based negative symptoms? Some reviewers conclude that it is scant for clozapine, contending that any impact on negative features reflects a greater efficacy for positive symptoms in neurolepticrefractory patients, combined with lesser extrapyramidal side-effects (Tandon et al. 1993; Carpenter et al. 1995; Jibson \& Tandon, 1996). Clozapine patients are typically refractory in North American trials, leaving greater room for positive symptom improvement and the secondary gains in negative symptoms that follow. Tandon et al. (1993) also cite correlations between positive and negative symptom gains (suggesting that improvement in negative symptoms does not occur independently of positive symptom gains), but acknowledge that unrelated mechanisms with similar time courses may be responsible.

In contrast, Moller et al. (1995) have demonstrated via path analysis that reductions in negative symptoms in large risperidone trials are not fully accounted for by reductions in positive symptoms or EPS. Similarly, Miller et al. (1994) reported that although improvements in affective flattening, anhedonia/asociality, avoliton/apathy and alogia with clozapine correlated with improvement in 
disorganization, suggesting these effects could have been secondary, an examination of time lines (to see what preceded what) and regression analyses indicated that these were instead parallel, independent changes. They found no correlations between positive and negative symptoms, or between improvements in EPS or depression and negative symptoms, and concluded that a portion of clozapine's effect on negative symptoms is mediated through a direct effect on an underlying, primary, pathophysiology.

These issues are far from resolved (see, for example, the debate regarding clozapine between Meltzer, $1995 a$ and Carpenter, et al. 1996, with commentary from Kane, 1996) and it would appear that well-controlled trials with predominantly negative symptom patients are required to move beyond the impasse (Kane, 1996). In the meantime, we may ask: By what mechanisms might the medications exert a direct effect upon negative symptoms?

Specific theoretical mechanisms have seldom been elucidated beyond a general expectation that the potent 5- $\mathrm{HT}_{2}$ antagonism of the newer agents (combined with a low degree of $\mathrm{D}_{2}$ blockade) is somehow involved (e.g. Megens et al. 1994). The mood elevating effects of 5- $\mathrm{HT}_{2}$ antagonists may improve drive above and beyond gains attributable to reversal of state-dependent dysphoria. 5- $\mathrm{HT}_{2}$ antagonism may activate prefrontal cortex dopamine projections, an effect somewhat akin to that demonstrated with amphetamines (Svensson et al. 1995); Pickar et al. (1990) have noted that negative symptoms respond better when DA agonists are administered concurrently with neuroleptics. In this and similar models, schizophrenia reflects both hyper- and hypo-dopaminergic activity, with excessive activity in some systems causing positive symptoms, and insufficiencies elsewhere underlying the negative features.

Animal findings are also suggestive. Risperidone increases social interaction between unfamiliar rats (like clozapine, but unlike haloperidol; Megens et al. 1994) and olanzapine exhibits anxiolytic properties (Moore et al. 1992). Associations between social anxiety related behaviours and negative symptoms (Penn et al. 1994) suggest that chronic anxiety is implicated in schizophrenic withdrawal; to the extent that this is true, the anxiolytic properties of these medications could foster improved sociality in patients. Clozapine is a potent blocker of limbic DA receptor binding (Pickar et al. 1990), and both clozapine and olanzapine act in ways that suggest they will attenuate the diminished prepulse inhibition of startle reflex that many schizophrenics display (Tollefson, 1996).

Clozapine may correct P50 auditory evoked response habituation abnormalities, whereas neuroleptics do not (Nagamoto et al. 1996). These abnormalities - in which patients fail to show normal inhibition to the second of a pair of stimuli-may reflect a hippocampal-systems dysfunction and occur in most schizophrenics (Freedman et al. 1997). The possibility that an amelioration of this abnormality has good clinical effect on social behaviour (via normalization of a limbic abnormality) is intriguing, though far from established. There are firmer grounds for thinking that improvements in cognition will flow from a correction of this habituation failure. The P50 abnormality correlates with impaired performances on measures of sustained attention and word recognition, possibly reflecting failures in neural mechanisms that filter sensory input to higher brain centres (Freedman et al. 1997); thus distractibility results.

More fundamentally, the extent to which negative symptoms and cognition will respond hand in hand remains uncertain. Along with some negative features, some attentional deficits improve with neuroleptic treatment of acute states (Spohn \& Strauss, 1989). The tendency of cognitive deficits and negative symptoms to correlate and persist beyond acute states suggests a common neuropathological basis; so too does the relationship of both to early onset, and to eye-tracking, brain structural, and frontal perfusion/metabolism abnormalities (Kirkpatrick et al. 1989; AlaghbandRad et al. 1997; Goldman, 1998). The association with neuroanatomical abnormalities suggest that significant gains in either are unlikely. Other relationships, such as the association with hypofrontality, suggest hope for a pharmacological 'tuning' of systems involved in drive, initiation and behavioural organization. These hopes are bolstered by post-mortem findings of 5-HT, DA and glutamate abnormalities that relate to ante-mortem cognitive status (Tollefson, 1996).

Although it seems reasonable to assume a degree of common causality, such that gains in one will be accompanied by gains in the other, it warrants noting that both negative symptoms and cognitive 
deficits are probably complexly underwritten. They are unlikely to improve in lock step; improvements in social drive could conceivably occur without a significant improvement in cognition, which could limit the impact of these gains on occupational functioning, for example. These remain empirical questions, best answered by the conjoint collection of symptom, cognition and broader adaptive functioning measures to validate the significance of treatment effects.

\section{NEUROPSYCHOLOGICAL OUTCOME DATA}

There is limited data on the neuropsychological effects of the novel antipsychotics other than clozapine, where outcomes have varied from not differing from neuroleptics (Classen \& Laux, 1988), despite clinical improvement (Goldberg et al. 1993), through to gains in aspects of cognition (Hagger et al. 1993; Meltzer, 1994, 1995 b; Lee et al. 1994; Mortimer et al. 1995). Negative effects have also been reported, particularly in aspects of memory functioning (Goldberg et al. 1993; Hoff, et al. 1993; Carter et al. 1994). Normal individuals experimentally taking clozapine performed poorly on a several neuropsychological tests and exhibited EEG effects similar to those of an anticholinergic antidepressant (Saletu et al. 1987).

Goldberg \& Weinberger's 1994 review and findings by Hoff et al. (1996) indicate that while clozapine may improve performance on tasks requiring readiness and rapid response (functions sometimes attributed to the basal ganglia), it impairs working memory. However, Gallhofer et al. (1996) report that clozapine improves performance on mazes, an effect in good measure likely to reflect improvements in working memory of the sort ascribed to frontal lobe activity. Goldberg \& Weinberger also concluded that visual memory is impaired by clozapine, acknowledging that the question as to why verbal memory would not also be affected remains unanswered, and there have been inconsistencies across studies in terms of tests showing gains. The precise nature of, and reasons for, clozapine effects on cognition therefore remain to be fully explicated.

There are additional reasons for not generalizing from clozapine to the newer agents. Clozapine is not prototypical of all novel antipsychotics. It is 20 to 50 times more potent in blocking muscarinic receptors than in blocking $\mathrm{D}_{2}$ receptors (Seeman, 1990), making it considerably more anticholinergic than many novel agents. Generalizability may also be limited insofar as clozapine samples typically have been highly treatment resistant, whereas other novel antipsychotics will be prescribed to broader, potentially more responsive, samples.

Data is emerging for other agents. Daniel (1994) reported that risperidone (relative to clozapine) improved visual memory and categories attained on the Wisconsin Card Sorting Test, whereas clozapine improved reaction time. Gallhofer et al. (1996) found no significant differences between risperidone and clozapine patients on maze tests, although both groups did better than untreated patients or those on neuroleptics. Other reports of risperidone-related improvements include an effect on verbal working memory that persisted after controlling for benzotropine cotreatment and changes in symptoms (Green et al. 1997), improvements in memory (Stip \& Lussier, 1997), and Wisconsin Card Sorting improvements that correlated with negative symptom gains (Rossi et al. 1997). Stip et al. (1996) report significant cognitive improvement in a patient treated with quetiapine and Meyer-Lindenberg et al. (1997) report zotepine related improvements in maze performance that exceeded those seen with clozapine. These findings sometimes rest on infirm methodology (e.g. lack of controls), or depend upon fine-grained analyses of subsections of larger data sets, leaving adaptive significance in doubt. There is hope, however, that even modest cognitive gains will parlay into significant improvements in functioning, even if indirectly mediated via enhanced insight, medication compliance and an improved capacity to benefit from rehabilitation training.

\section{CONCLUDING COMMENTS}

Schizophrenics function below their social and occupational potential because of their neurocognitive deficits (Meltzer et al. 1994; Meltzer, 1995a), so significant gains in the quality of life of many patients await the introduction of agents with ameliorative effects. Despite the salience of the issue and a now extensive literature on these medications, much remains to be learnt, 
principally because cognitive outcome has remained the poor cousin to clinical symptoms in efficacy studies.

There are grounds for optimism regarding the potential of novel agents to ameliorate adaptive functioning deficits. These partly rest on the likelihood that the novel compounds will exert fewer negative consequences than conventional neuroleptics, resulting in enhanced effectiveness via improved compliance. Deficits associated with neuroleptic motor effects, which may exacerbate the tendency to withdraw from normal life, should be diminished, and complications caused by the use of adjunctive anticholinergic medication with neuroleptics may be largely avoided. The 5- $\mathrm{HT}_{2}$ properties of the novel drugs may engender improved drive and sociality, ameliorations of negative features that could be accompanied by neuropsychological gains.

Despite some reports of positive findings, the grounds for thinking that the novel antipsychotics will exert direct and significant effects on neurocognition nevertheless remain largely inferential, and infirmly so, since theories about the underpinnings of schizophrenia, or drug mechanisms, often prove, with time, to be either over-simplifications or simply wrong. Novel medications are supplanting conventional neuroleptics as treatments of choice, and it behoves us to learn as much as possible about their neuropsychological effects: without extensive research, we simply cannot know what these are. Demonstrations of beneficial effects on cognition should be accompanied by investigations of the significance of these effects in everyday functioning terms (i.e. illness insight, quality of life, social, family and vocational data). These are important concerns, as any differences in response profiles that emerge across medications could influence both prescribing practices and future drug development.

K. A. HAWKINS, S. MOHAMED AND S. W. WOODS

\section{REFERENCES}

Alaghband-Rad, J., Hamburger, S. D., Giedd, J. N., Frazier, J. A. \& Rapoport, J. L. (1997). Childhood-onset schizophrenia: biological markers in relation to clinical characteristics. American Journal of Psychiatry 154, 64-68.

Andreasen, N. C., Rezai, K., Alliger, R., Swayze, V. W., Flaum, M., Kirchner, P., Cohen, G. \& O'Leary, D. S. (1992). Hypofrontality in neuroleptic-naive patients and in patients with chronic schizophrenia. Archives of General Psychiatry 49, 943-958.

Borison, R. L. (1995). Clinical efficacy of serotonin-dopamine antagonists relative to classic neuroleptics. Journal of Clinical Psychopharmacology 15 (suppl. 1), 24s-29s.

Breier, A., Schreiber, J. L., Dyer, J. \& Pickar, D. (1991). National Institute of Mental Health: longitudinal study of chronic schizophrenia: prognosis and predictors of outcome. Archives of General Psychiatry 48, 239-246.

Carpenter, W. T., Heinrichs, D. W. \& Wagman, A. M. I. (1988). Deficit and nondeficit forms of schizophrenia: the concept. American Journal of Psychiatry 145, 578-583.

Carpenter, W. T., Buchanan, R. W. \& Kirkpatrick, B. (1991). The concept of negative symptoms of schizophrenia. In Negative Schizophrenic Symptoms: Pathophysiology and Clinical Implications (ed. J. F. Greden and R. Tandon), pp. 3-20. American Psychiatric Press: Washington DC.

Carpenter, W. T., Conley, R. R., Buchanan, R. W., Brier, A. \& Tamminga, C. A. (1995). Patient response and resource management: another view of clozapine treatment of schizophrenia. American Journal of Psychiatry 152, 827-832.

Carpenter, W. T., Conley, R. R., Buchanan, R. W., Brier, A. \& Tamminga, C. A. (1996). Clozapine conflict. American Journal of Psychiatry 153, 1505-1507.

Carter, J., Thrasher, S. \& Thornicroft, G. (1994). Cognitive impairment and clozapine. British Journal of Psychiatry 164, 132-133.

Chouinard, G., Jones, B., Remington, G., Bloom, D., Addington, D., MacEwan, G. W., Labelle, A. \& Beauclair, L. (1993). A Canadian multicenter placebo controlled study of fixed doses of risperidone and haloperidol in the treatment of chronic schizo- phrenic patients. Journal of Clinical Psychopharmacology 13, 25-40.

Classen, W. \& Laux, G. (1988). Sensorimotor and cognitive performance of schizophrenic inpatients treated with haloperidol, flupenthixol, or clozapine. Pharmacopsychiatry 21, 295-297.

Cohen, H. \& Cohen, D. (1993). What may be gained from neuropsychological investigation of tardive dyskinesia? Brain and Cognition 23, 1-7.

Crow, T. J. (1991). Current view of the type II syndrome: significance of age of onset, intellectual impairment, and structural changes in the brain. In Negative Schizophrenic Symptoms: Pathophysiology and Clinical Implications. (ed. J. F. Greden \& R. Tandon), pp. 161-171. American Psychiatric Press: Washington, DC.

Daniel, D. G. (1994). Comparison of risperidone and clozapine on clinical and cognitive functions in psychotic disorders (abstract). Biological Psychiatry 35, 667.

Freedman, R., Coon, H., Myles-Worsley, M., Orr-Urtreger, A., Olincy, A., Davis, A., Polymeropoulos, M., Holik, J., Hopkins, J., Hoff, M., Rosenthal, J., Waldo, M. C., Reimherr, F., Wender, P., Yaw, J., Young, D. A., Breese, C. R., Adams, C., Patterson, D., Adler, L. G., Kruglyak, L., Leonard, S. \& Byerley, W. (1997). Linkage of a neurophysiological deficit in schizophrenia to a chromosome 15 locus. Proceedings of the National Academy of Sciences, USA 94, 587-592.

Gallhoffer, B., Bauer, U., Lis, S., Krieger, S. \& Gruppe, H. (1996). Cognitive dysfunction in schizophrenia: comparison of treatment with atypical antipsychotic agents and conventional neuroleptic drugs. European Neuropsychopharmacology 6 S2, 13-20.

Gelders, Y. G. (1989). Thymosthenic agents, a novel approach to the treatment of schizophrenia. British Journal of Psychiatry 155 (suppl. 5), 33-36.

Goldberg, T. E. \& Weinberger, D. R. (1994). The effect of clozapine on neurocognition: an overview. Journal of Clinical Psychiatry 55 (suppl. B), 88-90.

Goldberg, T. E., Gold, J. M. \& Braff, D. L. (1991). Neuropsychological functioning and time-linked information processing in schizophrenia. In Review of Psychiatry (vol. 10) (ed. A. Tasman and S. M. Goldfinger), pp. 60-78. American Psychiatric Press: Washington, DC. 
Goldberg, T. E., Greenberg, R. D., Griffith, S. J., Gold, J. M., Kelinman, J. E., Pickar, D., Schulz, S. C. \& Weinberger, D. R. (1993). The effect of clozapine on cognition and psychiatric symptoms in patients with schizophrenia. British Journal of Psychiatry 162, 43-48.

Goldman, R. S. (1998). Neuropsychological dysfunction and schizophrenia: implications for pharmacotherapy. Essential Psychopharmacology (in the press).

Green, M. F. (1996). What are the functional consequences of neurocognitive deficits in schizophrenia? American Journal of Psychiatry 153, 321-330.

Green, M. F., Marshall, B. D., Wirshing, W. C., Ames, D., Marder, S. R., McGurk, S., Kern, R. S. \& Mintz, J. (1997). Does risperidone improve verbal working memory in treatment-resistant schizophrenia? American Journal of Psychiatry 154, 799-804.

Hagger, C., Buckley, P., Kenny, J. T., Friedman, L., Ubogy, D. \& Meltzer, H. (1993). Improvement in cognitive functions and psychiatric symptoms in treatment-refractory schizophrenic patients receiving clozapine. Biological Psychiatry 34, 702-712.

Hawkins, K. A., Hoffman, R. E., Quinlan, D. M., Rakfeldt, J., Docherty, N. M. \& Sledge, W. H. (1997). Cognition, negative symptoms, and diagnosis: a comparison of schizophrenic, bipolar, and control samples. Journal of Neuropsychiatry and Clinical Neurosciences 9, 81-89.

Hoff, A. L., Weineke, M., DeVilliers, D., et al. (1993). Effects of clozapine on cognitive functioning. In New Research Program and Abstracts of the 146th Annual Meeting of the American Psychiatric Society, May 15, 1993; San Francisco, Calif. Abstract NR254: 124.

Hoff, A. L., Faustmann, W. O., Weineke, M., Espinoza, S., Costa, M., Wolkowitz, O. \& Csernansky, J. G. (1996). The effects of clozapine on symptom reduction, neurocognitive functioning, and clinical management in treatment-refractory state hospital schizophrenic patients. Neuropsychopharmacology 15, 361-369.

Huttunen, M. (1995). The evolution of the serotonin-dopamine, antagonist concept. Journal of Clinical Psychopharmacology 15, $4 \mathrm{~s}-10 \mathrm{~s}$.

Jibson, M. D. \& Tandon, R. (1996). A summary of research findings on the new antipsychotic drugs. Psychiatry Forum 16, i-vii.

Kane, J. M. (1996). Commentary on the clozapine conflict. American Journal of Psychiatry 153, 1507-1508.

Kane, J. M. \& Freeman, H. L. (1994). Towards more effective antipsychotic treatment. British Journal of Psychiatry 165 (suppl. 25), 22-31.

Kirkpatrick, B., Buchanan, R. W., McKenney, P. D., Alphs, L. D. \& Carpenter, W. T. (1989). The schedule for the deficit syndrome: an instrument for research in schizophrenia. Psychiatry Research 30, 119-123.

Lee, M. A., Thompson, P. A. \& Meltzer, H. Y. (1994). Effects of clozapine on cognitive function in schizophrenia. Journal of Clinical Psychiatry 55 (suppl. B), 82-90.

Lieberman, J. A. (1996). New developments in antipsychotic drug treatment. Psychiatric Times March, 41-43.

Lidsky, T. I., Labuszewski, T. \& Levine, F. M. (1981). Are movemen disorders the most serious side effects of maintenance therapy with antipsychotic drugs? Biological Psychiatry 16, 1189-1194.

Mackay, A. V.P. (1980). Positive and negative symptoms schizophrenic symptoms and the role of dopamine. British Journal of Psychiatry 170, 379-386.

Marder, S. R. \& Meibach, R. C. (1994). Risperidone in the treatmen of schizophrenia. American Journal of Psychiatry 151, 825-835.

Meco, G., Bedini, L., Bonifati, V. \& Sonsini, U. (1989). Risperidone in the treatment of chronic schizophrenia with tardive dyskinesia. Current Therapeutic Research 46, 876-883.

Megens, A. A. H. P., Awouters, F. H. L., Schott, A., Meert, T. F., Dugovic, C., Niemegeers, C. J. E. \& Leysen, J. E. (1994). Survey on the pharmacodynamics of the new antipsychotic risperidone. Psychopharmacology 114, 9-23.

Meltzer, H. Y. (1992). Dimensions of outcome with clozapine. British Journal of Psychiatry 160, (suppl. 17), 46-53.
Meltzer, H. Y. (1994). An overview of the mechanisms of action of clozapine. Journal of Clinical Psychiatry 55 (suppl. B), 47-52.

Meltzer, H. Y. (1995a). Clozapine: is another view valid? American Journal of Psychiatry 152 (6), 821-825.

Meltzer, H. Y. (1995b). Multiple-outcome criteria in schizophrenia : an overview of outcome with clozapine. Treatment resistant schizophrenia in perspective: assessment and management. European Psychiatry 10 (suppl. 1), 19s-25s

Meltzer, H. Y., Lee, M. A. \& Ranjan, R. (1994). Recent advances in the pharmacotherapy of schizophrenia. Acta Psychiatrica Scandinavia 90 (suppl. 384), 95-101.

Meyer-Lindenberg, H., Gruppe, H., Bauer, U., Krieger, S. \& Gallhofer, B. (1997). Improvement of cognitive function in schizophrenic patients receiving clozapine or zotepine: results from a double-blind study. Pharmacopsychiatry 30, 35-42.

Miller, D. D., Perry, P. J., Cadoret, R. J. \& Andreasen, N. C. (1994) Clozapine's effect on negative symptoms in treatment refractory schizophrenics. Comprehensive Psychiatry 35, 8-15.

Moller, H. J., Muller, H., Borison, R. L., Schooler, N. R. \& Chouinard, G. (1995). A path-analytical approach to differentiate between direct and indirect drug effects on negative symptoms in schizophrenic patients. European Archives of Psychiatry and Clinical Neurosciences $\mathbf{2 4 5}, 45-49$

Moore, N. A., Tye, N. C., Axton, M. S. \& Risius, F. C. (1992). The behavioral pharmacology of Olanzapine, a novel 'atypical' antipsychotic agent. The Journal of Pharmacology and Experimental Therapeutics 262, 545-551.

Mortimer, A. M., Smith, A., Lock, M., Lekh, S. \& Rooke-Ley, S. (1995). Clozapine and neuropsychological function: preliminary report of a controlled study. Human Psychoharmacology Clinical and Experimental 10, 157-158.

Mukherjee, S., Reddy, R. \& Schnur, D. B. (1991). A developmental model of negative syndromes in schizophrenia. In Negative Schizophrenic Symptoms: Pathophysiology and Clinical Implications (ed. J. F. Greden and R. Tandon), pp. 173-185. American Psychiatric Press: Washington, DC

Nagamoto, H. T., Adler, L. E., Hea, R. A., Griffith, J. M., McCrae, K. A. \& Freedman, R. (1996). Gating of Auditory P50 in schizophrenia: unique effects of clozapine. Biological Psychiatry 40, 181-188.

Nuechterlein, K. H. \& Subotnik, K. L. (1996). The role of neurocognitive deficits in understanding adaptive functioning in severe psychiatric illness: commentary on Hawkins and Cooper. Psychiatry 59, 389-392.

Penn, D. L., Hope, D. A., Spaulding, W. \& Kucera, J. (1994). Social anxiety in schizophrenia. Schizophrenia Research 11, 277-284.

Perlick, D., Mattis, S., Stastny, P. \& Silverstein, B. (1992). Negative symptoms are related to both frontal and nonfrontal neuropsychological measures in chronic schizophrenia. Archives of General Psychiatry 49, 245-246.

Pickar, D., Litman, R. E., Konicki, P. E., Wolkowitz, O. M. \& Brier, A. (1990). Neurochemical and neural mechanisms of positive and negative symptoms in schizophrenia. In Schizophrenia: Positive and Negative Symptoms and Syndromes (ed. N. C. Andreasen), pp. 124-151. Karger: Basel.

Pogue-Geile, M. F. \& Harrow, M. (1985). Negative symptoms in schizophrenia: their longitudinal course and prognostic significance. Schizophrenia Bulletin 11, 427-439.

Richelson, E. (1996). Preclinical pharmacology of neuroleptics: focus on new generation compounds. Journal of Clinical Psychiatry 57 (suppl. 11), 4-11

Rossi, A., Mancini, F., Stratta, P., Mattei, P., Gismondi, R., Pozzi, F. \& Casacchia, M. (1997). Risperidone, negative symptoms and cognitive deficit in schizophrenia: an open study. Acta Psychiatrica Scandinavia 95, 40-43.

Saletu, B., Kufferle, J., Grunberger, J., Linzmayer, L., Foldes, P., Topitz, A. \& Anderer, P. (1987). Comparative placebo-controlled pharmacodynamic studies with zotepine and clozapine utilizing pharmaco-EEG and psychometry. Pharmacopsychiatry 20, 12-27. Saykin, A. J., Shtasel, D. L., Gur, R. E., Kester, D. B., Mozley, 
L. H., Stafiniak, P. \& Gur, R. C. (1994). Neuropsychological deficits in neuroleptic naive patients with first episode szhizophrenia. Archives of General Psychiatry 51, 124-131.

Schooler, N. R. (1994). Negative symptoms in schizophrenia: assessment of the effect of risperidone. Journal of Clinical Psychiatry 55 (suppl.), 22-28.

Seeman, P. (1990). Atypical neuroleptics: role of multiple receptors, endogenous dopamine, and receptor linkage. Acta Psychiatrica Scandinavica 82 (suppl. 358), 14-20.

Spohn, H. E. \& Strauss, M. E. (1989). Relation of neuroleptic and anticholinergic medication to cognitive function in schizophrenia. Journal of Abnormal Psychology 98, 367-380.

Stip, E. \& Lussier, I. (1996). The effects of risperidone on cognition in patients with schizophrenia.. Canadian Journal of Psychiatry $\mathbf{4 1}$ (suppl. 2), S35-S40.

Stip, E., Lussier, I., Babai, M. \& Fabian, J. L. (1996). Seroquel and cognitive improvement in patients with schizophrenia. Biological Psychiatry 40, 430-437.

Struve, F. A. \& Willner, A. E. (1983). Cognitive dysfunction and tardive dyskinesia. British Journal of Psychiatry 143, 597-600.

Svensson, T. H., Mathe', J. M., Andersson, B. M., Nomikos, G. G., Hildebrand, B. M. \& Marcus, M. (1995). Mode of action of atypical neuroleptics in relation to the phencyclidine model of schizophrenia: role of 5- $\mathrm{HT}_{2}$ receptor and alpha ${ }_{1}$-adrenoreceptor antagonism. Journal of Clinical Psychopharmacology 15 (suppl. 1), $11 \mathrm{~s}-18 \mathrm{~s}$.

Tandon, R., Goldman, R., DeQuardo, J. R. Goldman, M., Perez, M. \& Jibson, M. (1993). Positive and negative symptoms covary during clozapine treatment in schizophrenia. Journal of Psychiatric Research 27, 341-347.

Tollefson, G. D. (1996). Cognitive function in schizophrenic patients. Journal of Clinical Psychiatry 57 (suppl. 11), 31-39. 